\title{
I CAN BREATHE HERE: AN EXPLORATION OF AUTO-ETHNOGRAPHY, INTUITION AND EMBODIMENT IN DESIGN PROCESS
}

Katie Day

I perceive the wholeness of the world ... to live perception, to be perception itself ...

Lygia Clarke'

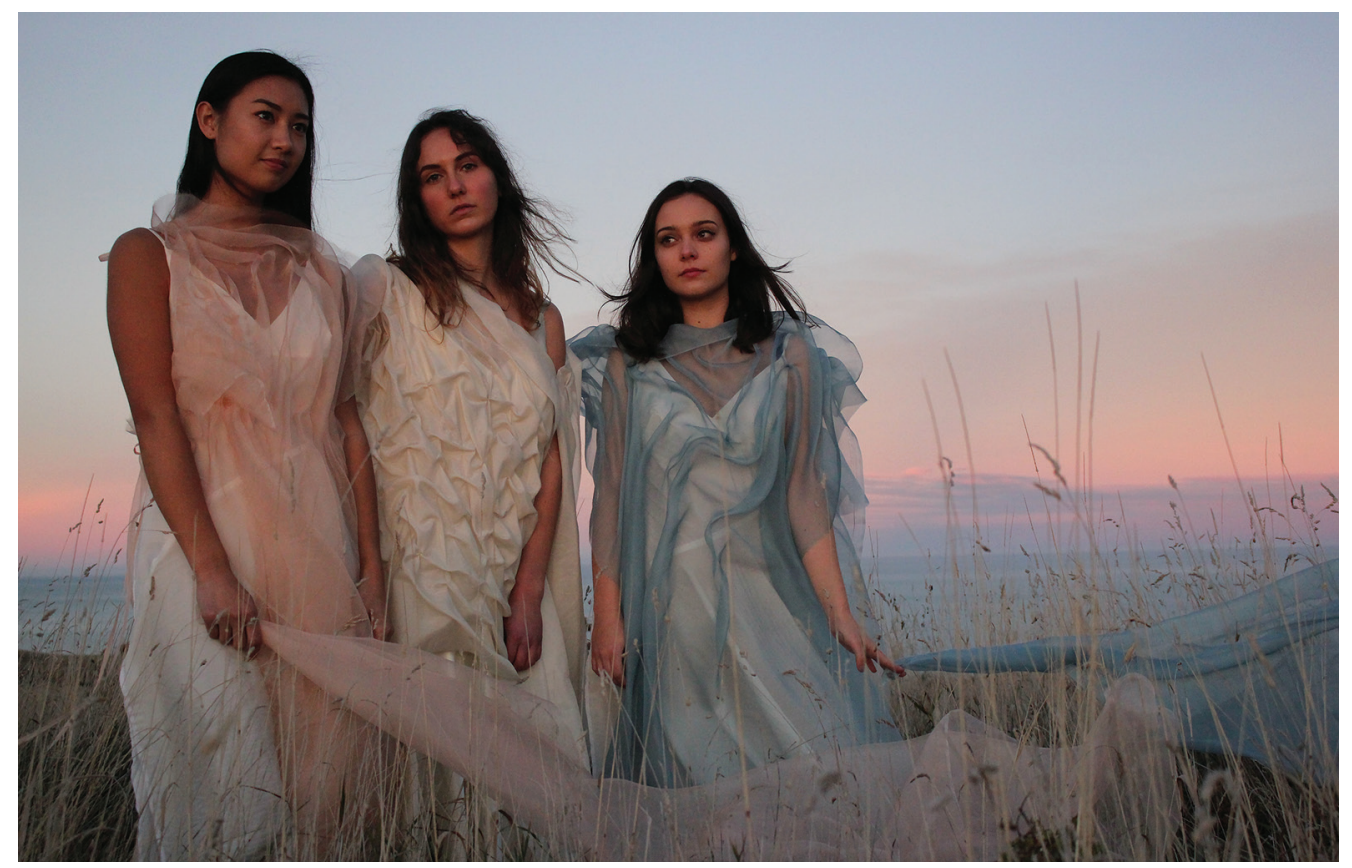

Figure I. Katie Day, I Can Breathe Here collection. 


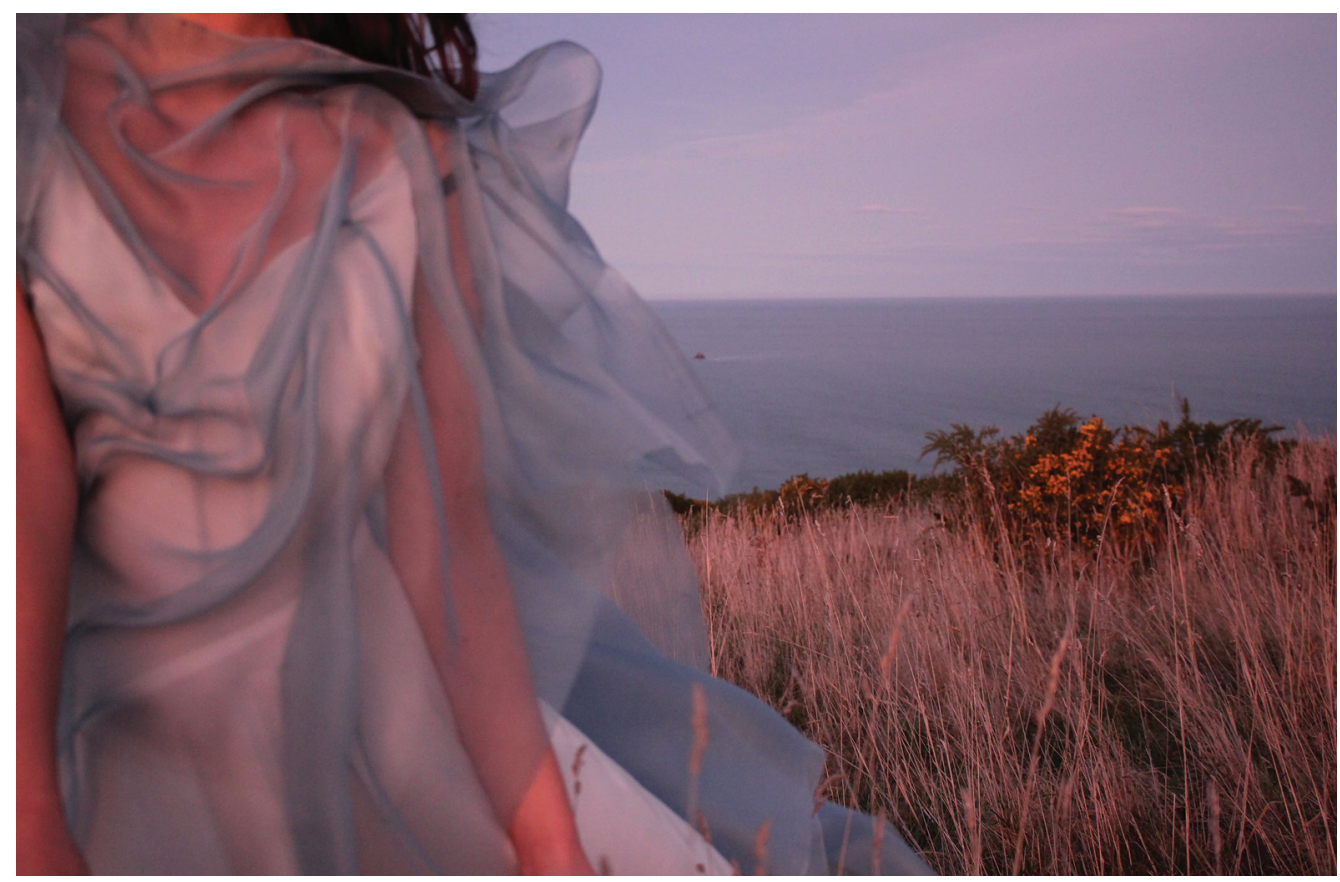

Figure 2. Katie Day, I Can Breathe Here. Example of sculpted silk and connection points.

I Can Breathe Here is a conceptual fashion collection that emerged from the rejection of my gravitation towards compartmentalisation and the wholehearted acceptance of my inherent desire for connectedness (Figure I).

I initially set out to create a collection steeped in structure and form through exploring the relationship between architecture and the body. These concepts had once offered a sense of familiarity, safety even; however, as I set off down this path, I quickly encountered internal tension, disconnection and distress. There was a separation, an expansive space between self and design. I was protecting my vulnerability, shielding true self, hiding behind structure and form. Yet the division between self and authentic created work was dangerously inhibiting the integrity of this collection. A bridge or a revelation was required to move forward. I chose both.

The revelation was that we as designers infuse ourselves into our concepts. The stories we tell draw consciously or unconsciously from personal experience - thus the concept cannot be completely separated from the designer. I could not keep a safe distance from my designs any longer. My experiences would relentlessly seep through, despite stubborn attempts to keep them protected, private. The bridge was built - rather than separating myself from my designs, why not just let go and embrace one's lived experience in the design process? An evolution in process had occurred. Rather than compartmentalising, keeping my designs clinical, safely structured and far from the soul, I would consciously choose to infuse my lived experience, values and observations into this collection.

With the theory and practice of auto-ethnography - described as "an approach to research and writing that seeks to describe and systematically analyze personal experience in order to understand cultural experience" ${ }^{2}$ - in mind, a new concept took form. Architecture and the body were still sources of inspiration, yet the process was personal now; I was connected to this collection and my sense of identity and place had weight to it. This was the fresh anchor point for my collection. I Can Breathe Here emerged as a collection exploring sense of place, belonging and connectedness, to the earth and to each other. 


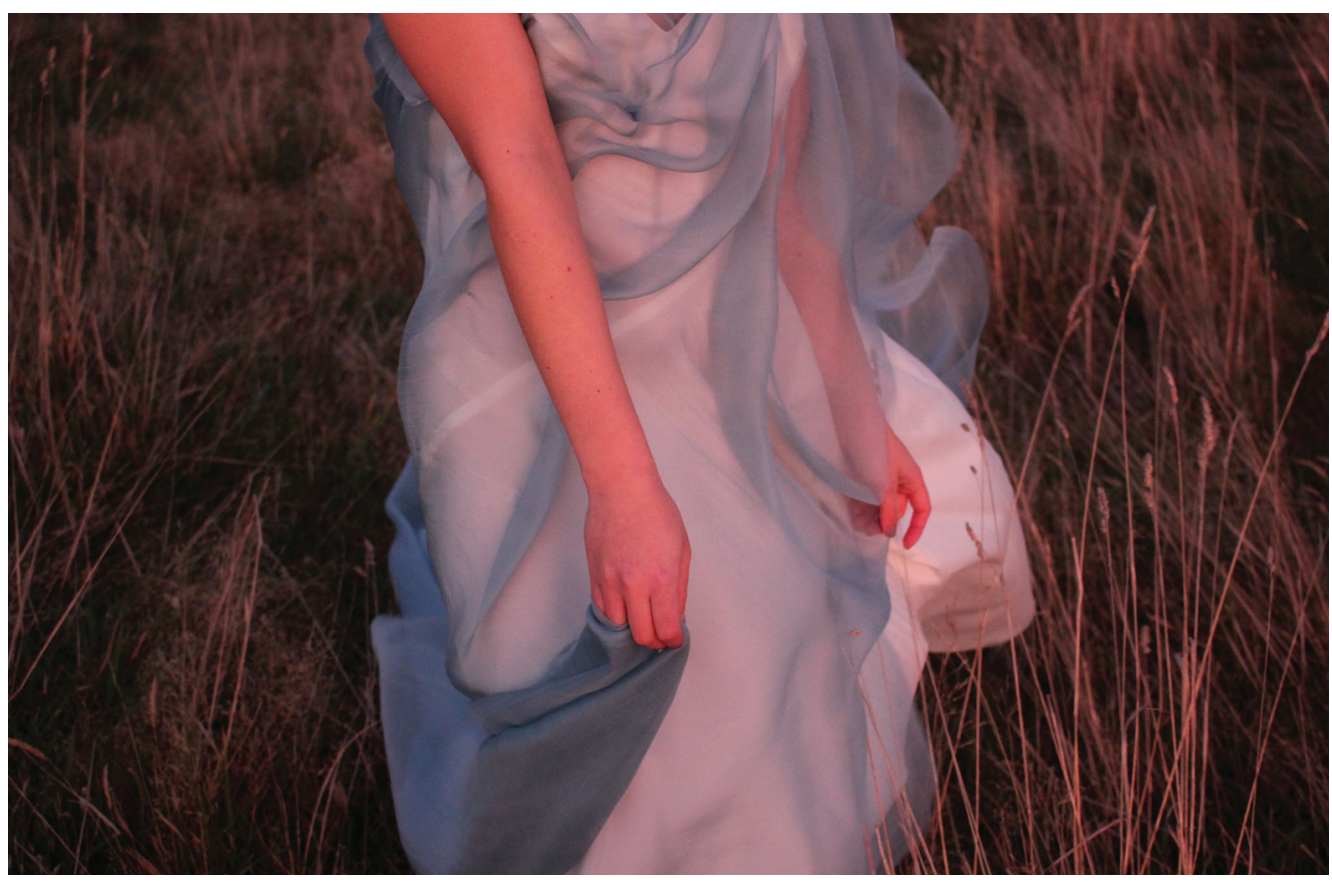

Figure 3. Katie Day, I Can Breathe Here. The body slips effortlessly through the silk.

\section{DISCOVERY}

A journey of discovery ensued as I became a student of myself and my environment. Referring to auto-ethnography, Andrea Short explains: "I believe that there is no boundary between myself as a person and myself as a designer - this method offers a great opportunity to bring these two aspects together."3 Auto-ethnography is a process of reflective observation and analysis of one's lived experience, considering time, place and culture, integrating elements of autobiography and ethnography.

I began to reflect on the land I adored and had known for a lifetime, Otepoti (Dunedin). I became mindful and heightened my awareness of all the thoughts, memories or experiences I had about the place. I ventured outside, physically exploring the land, driving from city limit to boundary line, walking as often as I could. The act of grounding was essential; I couldn't simply experience the environment with mind or memories. I needed to tangibly engage, barefoot to cool soil, hands submerged in icy waters, knees deep in tussocked hill, lungs expanded with crisp coastal air. I became connected. I immersed myself in the air, the ocean, the land and the light, and observed the narrative my thoughts would form.

I was magnetised to high places or water; naturally Otago Peninsula held my attention. I marvelled at the undulating peaks and valleys of the hills and found myself suspended in time as I stood at Taiaroa Head. Crest and trough of rhythmic waves hypnotised me as they met the break of land.

My observation of place was not reserved simply for grandeur or sacred moments, though. I captured my thoughts and feelings about this land in the mundane as well. "Autoethnographers recognize the innumerable ways personal experience influences the research process." ${ }^{\prime \prime}$ One of my journal entries reflected: "As I was driving to school today, I became aware of the hills on either side of me, a sense of peace filled my vehicle as I identified exactly how I felt. Held, but free. I was safely held within the hands of the land that surrounded me. I exhaled,'I can breathe here.' I can be."' 
My body of research was expanding as I collected thought upon thought about the air, light, breath, ground, height and the breadth of space I had encountered in Dunedin. I noted that a special term had made its way into my findings. It was "thin spaces," which could also be articulated as liminal spaces. Liminal spaces are the spaces that exist between things - a time, a season, a beginning or an end; they are the ambiguous, transitional spaces. Author Richard Rohr describes liminal spaces as places "where we are betwixt and between the familiar and the completely unknown. There alone is our old world left behind, while we are not yet sure of the new existence. That's a good space where genuine newness can begin."'5 My thin, liminal spaces were locations, often situated at points of arrival and departure around the coast, places of immense beauty, peace and minimal distraction where I felt a heightened level of connectedness to the land and to all beings. Having analysed the auto-ethnographic account I had made about my sense of place, three key words emerged: space, freedom and movement.

\title{
INTUITIVE MAKING AND EMBODIMENT
}

\author{
Maybe if I really believe in me, trust me, without any calculated plan, who knows \\ what will happen?
}

Eva Hesse ${ }^{6}$

Space. Freedom. Movement. These words became a mantra as I channelled my reflections of lived experience into fabric through an intuitive process of making. I meditated on these three words, and visualised the land as I set my hands to work on the fabric. I chose a soft, delicate, silk organza as my canvas due to its ability to represent weightlessness and capture light. I then began a process of repetitive motions, moulding and draping the silk to sculpt curves reflecting hills, rhythms reflecting water and twists depicting the wind patterns (Figure 2). I centred my thoughts on visualisation of place and meditative repetition of my mantra, disconnecting from preconceived notions of what a garment should be. The mind gave way to the hands and an embodied form of thinking led the way. "As the mind is embodied, the hand connected to the brain 'can see and feel and think' (Ufan 2004: 594), a process often described as thinking through the hands, thus defining making as a particular form of thinking."'

I draped the sculpted fabrics on the silhouette form, repeating the mantra: space, freedom, movement. I kept the connection points at the shoulders and sides minimal, creating garments that the body could slip through freely, yet still be enveloped by and connected to (Figure 3). I encountered a challenge as I attempted to communicate liminal space through the connection points in the garments, initially tacking the sculpted connection points with heavy, repetitive stitches. However, this created tension rather than ethereality. I drew from feedback I was given and explored hand-stitching options, finding a stitch that gently held the sculpted silk together, yet allowed for the in-between and gave space for the fabric to move and breathe (Figure 2). I crafted each connection point by hand, the stitching a continuous repetitive process that became an evening ritual, a practice of embodiment and a pathway out of overthought.

Natural Otago light is, at best, clear, illuminating and inspires a sense of wonder. The gradual, fading hues of dusk and dawn are particularly enchanting, often coaxing me into a dream-like state of reality. The silks' colour was chosen to reflect the natural light of dusk, the time of day I am most mesmerised by. Soft hues of salmon pink, dusty blue and crisp ivory encapsulate the remnants of fading daylight (Figure 4).

Connectedness wove itself through every aspect of this collection. Reflecting on my kinship to the land, it was crucial that I chose materials and construction techniques that had minimal impact on the Earth. I chose silk and silk-cotton, natural fibres that can biodegrade and, one day, peacefully return to the land. Unfortunately, a compromise had to be made in fabrication of the silk slip dresses. Although the dresses were primarily composed of silk, they did contain 3 percent Lycra and though this percentage is small, every fibre has a life cycle and this was not ideal. In future, all my garments will be composed of one hundred percent natural or recycled fibres. I would also like to explore natural dyes, sourced from local waste products, to reinforce the influence of place on a collection and to minimise the 


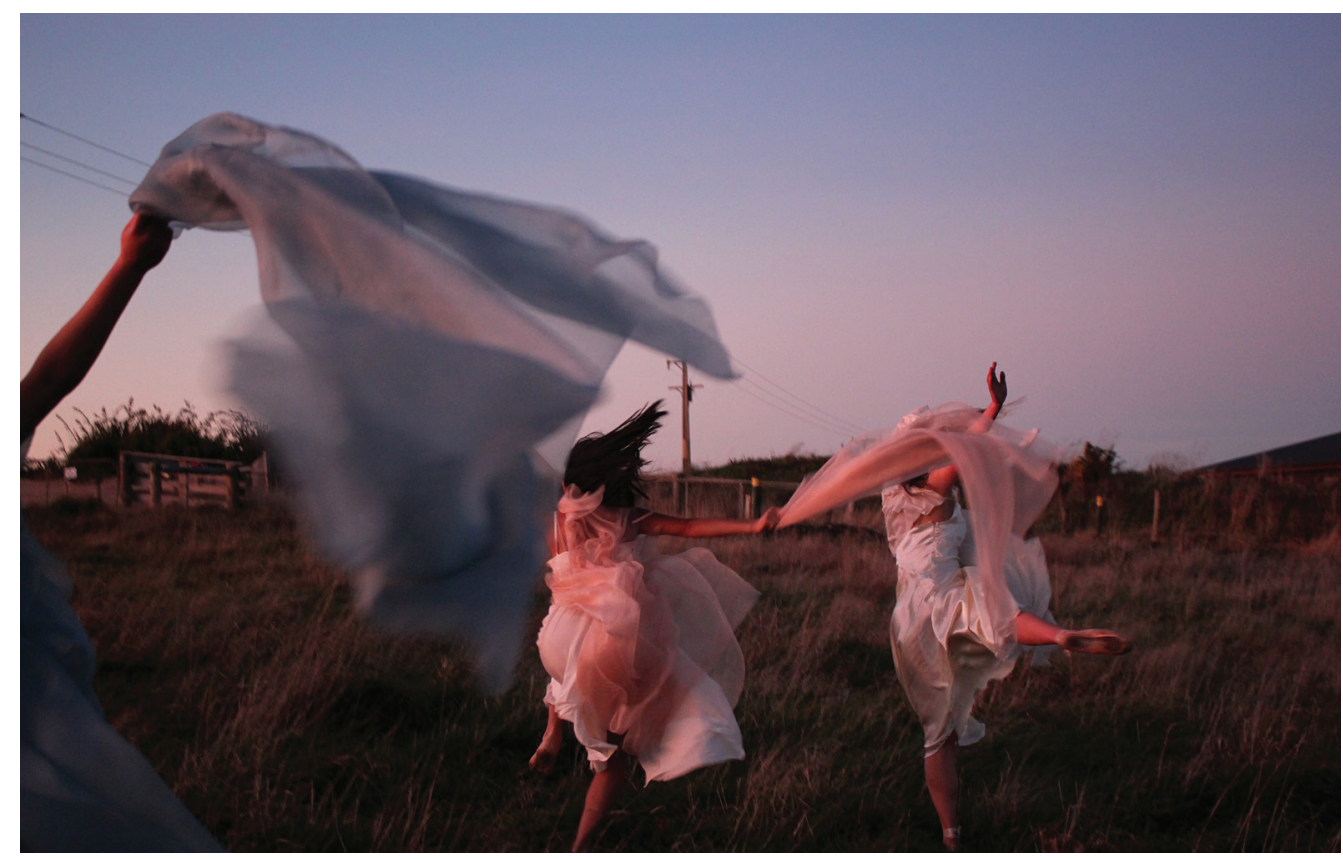

Figure 4. Katie Day, I Can Breathe Here. The soft hues of fading daylight are captured as the models embody my design values of space, freedom and movement.

impact that the fabric-colouring process has on the waterways and our environment. The outer, sculpted garments were made using zero-waste patternmaking techniques, sculpting individual, chosen lengths of silk. Form was created through the surface manipulation of the fabric, void of any cutting.

Through the use of zero-waste techniques, this collection represents an evolution of my sustainable practices. As designers, we are problem-solvers and storytellers and sustainability must be at the forefront of our minds. We are constantly learning, growing and re-evaluating our practices and each step to sustainability counts as we are all walking down the necessary path of change.

\section{CONCLUSION}

Isn't success, in the case of artists, the ability to express one's ideas to whatever public might be touched by that expression? Like many creative ideas, it is not necessarily the originality of the premise that is important or that defines the 'art' but the means and purity of its expression.

Maison Martin Margiela ${ }^{8}$

I Can Breathe Here is a great exhalation. A letting go. This collection allowed walls to fall in thought and process and provided a pathway for deepened connection between self and design. Place, belonging and connectedness, explored through auto-ethnography and expressed through an intuitive and embodied process of making, reinforced my sense of identity and presence. This collection is a personal journal given fabric form, and is a gentle reminder that vulnerability is strength, not weakness. My desire for connectedness to the earth and with each other has revealed itself with salient clarity, and our togetherness is the story I will continue to explore, unfold and expand upon throughout future collections. 
Katie Day is a final-year Bachelor of Design student majoring in fashion at Otago Polytechnic in Dunedin, New Zealand. Reflection, observation, embodiment and intuition guide her design process as she endeavours to tell stories of connectedness through exploration of vulnerability and regenerative action.

I Lygia Clarke, quoted in Stephen Horne, "Embodying Subjectivity," in Material Matters: The Art and Culture of Contemporary Textiles, eds Ingrid Bachmann and Ruth Scheuing (Toronto, ON:YYZBOOKS, 1998), 35.

2 Carolyn Ellis, Tony E Adams, and Auther P Bochner, "Autoethnography: An Overview," Historical Social Research, 36:4 (20I I), 273.

3 Andrea Short, "An Autoethnographic Reflection on Conceptual Fashion Textiles," Scope:Art \& Design, I5 (2017), 137.

4 Ellis, Adams and Bochner, "Autoethnography," 274.

5 Richard Rohr, Everything Belongs: The Gift of Contemplative Prayer (New York: Crossroad Publishing Company, 1999).

6 Cindy Nemser, "An Interview with Eva Hesse," Artforum (May 1970), 59-63, https://www.hauserwirth.com/stories/I4479interview-eva-hesse.

7 Solveigh Goett, "Materials, Memories and Metaphors," in The Handbook of Textile Culture, eds Janis Jefferies, Diana Wood Conroy and Hazel Clark (London: Bloomsbury Academic, 20I5), 127.

8 Maison Martin Margiela, quoted in Susannah Frankel, "The Birth, Death, and Re-birth of Conceptual Fashion," in Maison Martin Margiela, Maison Martin Margiela (New York: Rizzoli, 2009). 